Article

\title{
Impact of Satellite Remote Sensing Data on Simulations of Coastal Circulation and Hypoxia on the Louisiana Continental Shelf
}

\author{
Dong S. Ko ${ }^{1, *}$, Richard W. Gould Jr. ${ }^{1}$, Bradley Penta ${ }^{1}$ and John C. Lehrter ${ }^{2}$ \\ 1 Naval Research Laboratory, Oceanography Division, Stennis Space Center, MS 39529, USA; \\ gould@nrlssc.navy.mil (R.W.G.J.); penta@nrlssc.navy.mil (B.P.) \\ 2 U.S. EPA, Office of Research and Development, Gulf Breeze, FL 32561, USA; lehrter.john@epa.gov \\ * Correspondence: ko@nrlssc.navy.mil; Tel.: +1-288-688-5448
}

Academic Editors: Deepak R. Mishra and Prasad S. Thenkabail

Received: 30 March 2016; Accepted: 17 May 2016; Published: 23 May 2016

\begin{abstract}
We estimated surface salinity flux and solar penetration from satellite data, and performed model simulations to examine the impact of including the satellite estimates on temperature, salinity, and dissolved oxygen distributions on the Louisiana continental shelf (LCS) near the annual hypoxic zone. Rainfall data from the Tropical Rainfall Measurement Mission (TRMM) were used for the salinity flux, and the diffuse attenuation coefficient (Kd) from Moderate Resolution Imaging Spectroradiometer (MODIS) were used for solar penetration. Improvements in the model results in comparison with in situ observations occurred when the two types of satellite data were included. Without inclusion of the satellite-derived surface salinity flux, realistic monthly variability in the model salinity fields was observed, but important inter-annual variability was missed. Without inclusion of the satellite-derived light attenuation, model bottom water temperatures were too high nearshore due to excessive penetration of solar irradiance. In general, these salinity and temperature errors led to model stratification that was too weak, and the model failed to capture observed spatial and temporal variability in water-column vertical stratification. Inclusion of the satellite data improved temperature and salinity predictions and the vertical stratification was strengthened, which improved prediction of bottom-water dissolved oxygen. The model-predicted area of bottom-water hypoxia on the Louisiana shelf, an important management metric, was substantially improved in comparison to observed hypoxic area by including the satellite data.
\end{abstract}

Keywords: TRMM; MODIS; Louisiana shelf; coastal hypoxia; NCOM-LCS ocean model

\section{Introduction}

Ocean models with adequate parameterization, boundary conditions, forcing, and validation can provide important information describing past (hindcast), current (nowcast), and future (forecast) states of the ocean from global to regional and local scales, e.g., [1]. Hydrodynamic models can improve understanding of a wide variety of processes; including heat transfer, advection, mixing, and material transport. Further, coupling hydrodynamics with biogeochemical observations and models that characterize nutrient, carbon, and oxygen dynamics and food web interactions can provide products for specific applications, such as formulation of nutrient and carbon budgets or distribution maps of dissolved oxygen [2-4].

Remote sensing data from satellite are often assimilated to improve the model estimations; they provide synoptic data with better spatial coverage than in situ data, but typically only surface distributions are obtained, without any vertical information. The remote sensing data can also be used as a surface forcing. This approach is used here for the Tropical Rainfall Measurement Mission (TRMM) and Moderate Resolution Imaging Spectroradiometer (MODIS) data. 
Surface salinity flux and penetration of solar irradiance directly impact surface-layer heat content, water column stratification, and thermohaline circulation in the ocean. Thus, accurate estimates of both of these properties are essential in ocean circulation models. The surface salinity flux, the net balance between precipitation and evaporation, is typically estimated as the difference between the surface salinity analysis from a data assimilation system and the surface salinity from the ocean model (details are described in Section 2.5). The ocean solar shortwave transparency is generally parameterized as a single, spatially-invariant Jerlov oligotrophic optical water type [5]. These approaches are generally adequate in open-ocean regions, but as we will discuss, can cause problems in more complex coastal waters.

In this study, we developed a high resolution coastal model covering a portion of the northern Gulf of Mexico coast to study coastal circulation, and its impact on nutrient transport [3] and hypoxia development. Every summer off the coast of Louisiana west of the Mississippi River delta, an extensive zone of hypoxic bottom water forms (characterized by dissolved oxygen concentrations below $2 \mathrm{mg} / \mathrm{L}$ or $64 \mathrm{mmol} / \mathrm{m}^{3}$ ), primarily as a result of the decay of organic matter, produced either locally (due to enhanced nutrient concentrations) [6] or transported into the area from terrestrial sources [7]. However, water column stratification is an important prerequisite as well, leading to reduced mixing and limited ventilation of bottom waters [8]. The size of hypoxic zone varies from year-to-year, and over the past 30 years has ranged from a minimum of $4400 \mathrm{~km}^{2}$ in 2000 to $22,000 \mathrm{~km}^{2}$ in 2002 [9]. From a management perspective, the goal is to reduce the size of the hypoxic zone (through upstream nutrient reductions) to a five-year running average of less than $5000 \mathrm{~km}^{2}$ [10], a goal that has yet to be achieved. Modeling results can provide important insight into the relative importance of the various forcing processes on hypoxia development and may be used to identify how nutrient reductions impact hypoxic area size [11-13].

Over the course of model development described herein, we observed that the simulations failed to accurately reproduce observed stratification, particularly on the inner Louisiana shelf $(<50-\mathrm{m}$ depth), due mainly to insufficient representation of the solar penetration and surface salinity flux. In coastal areas, salinity is strongly influenced by interaction of the higher-salinity offshore waters with freshwater river discharge and precipitation, so improved spatial/temporal estimates of surface salinity flux (evaporation minus rainfall) are required for realistic salinity simulation. Spatial variability in the optical fields is also greater in coastal zones, and the coherence scales are much shorter than those in offshore waters due to for example, higher absorption in river plume and higher concentrations of chlorophyll $a$, chromophoric dissolved organic matter, and suspended particulate matter in inshore water. Thus, characterization of the light attenuation as a single, uniform value across the domain is not adequate; the excessive solar penetration can lead to overheating of the bottom waters in shallow areas [14].

Satellite remote sensing can provide synoptic surface data to estimate both the surface salinity flux and the solar penetration, with the potential to improve simulations. We explore this possibility by prescribing the surface salinity flux as the difference between rainfall estimated from TRMM and evaporation estimated from the Navy Operational Global Atmospheric Prediction System (NOGAPS). Similarly, we used spatially varying MODIS derived diffuse attenuation coefficient of sea water to prescribe the vertical extinction of solar irradiance.

To assess the effect of including the satellite data, we performed a twin experiment applying the model and compared the model temperature and salinity fields as well as the simulated hypoxia areas on the Louisiana Continental Shelf (LCS). One simulation did not incorporate satellite data (reference run) and one used satellite data to estimate both surface salinity flux and light attenuation (test run). In addition, we coupled the circulation model to a Simplified Dissolved Oxygen (SDO) hypoxia model to estimate the distribution of hypoxic bottom waters on the LCS. We assessed the improvement in the model results when the two types of satellite data were included through comparisons with in situ measurements.

The paper is organized as follows. The ocean hydrodynamic model and forcing are described in Section 2. The simplified dissolved oxygen model is presented in Section 3. The satellite remote sensing 
data including Kd from MODIS and rainfall from TRIMM are described in Section 4. Comparisons of model twin experiment with and without satellite data are presented in Section 5. Conclusions are provided in Section 6.

\section{Ocean Circulation Model}

\subsection{Ocean Model Configuration}

The ocean circulation model used in this study is an application of the US Naval Research Laboratory's Ocean Nowcast/Forecast System [15] on the Louisiana Continental Shelf. The NRL Ocean Nowcast/Forecast System is an integration of a data-assimilating, dynamical ocean model, a statistical data-analysis model, and various data streams for ocean bathymetry, climatological data, surface forcing, open boundary forcing, and observations for data assimilation. The dynamic model within the system is the Navy Coastal Ocean Model (NCOM) [16]; therefore we denote the model as NCOM-LCS.

The NCOM-LCS model domain covers entire Louisiana Continental Shelf, Mississippi Sound, and part of the Gulf of Mexico, extending from $27.4^{\circ} \mathrm{N}$ to $30.4^{\circ} \mathrm{N}$ and from $88.2^{\circ} \mathrm{W}$ to $94.5^{\circ} \mathrm{W}$ (Figure 1). The NCOM-LSC is embedded in the regional Intra-Americas Sea Nowcast/Forecast System (IASNFS) $[17,18]$ that covers the Gulf of Mexico and Caribbean Sea and in turn IASNFS uses the Navy Global NCOM model [1] for boundary conditions. The NCOM-LSC model grid follows longitude-latitude lines with $1.9 \mathrm{~km}$ grid size on average. Vertically, there are 35 hybrid sigma-z levels in the model. Twenty equal spaced terrain-following sigma layers are used from the surface down to a depth of $100 \mathrm{~m}$ to better resolve the topography effects on the shelf and level coordinates are used below in deeper depths.

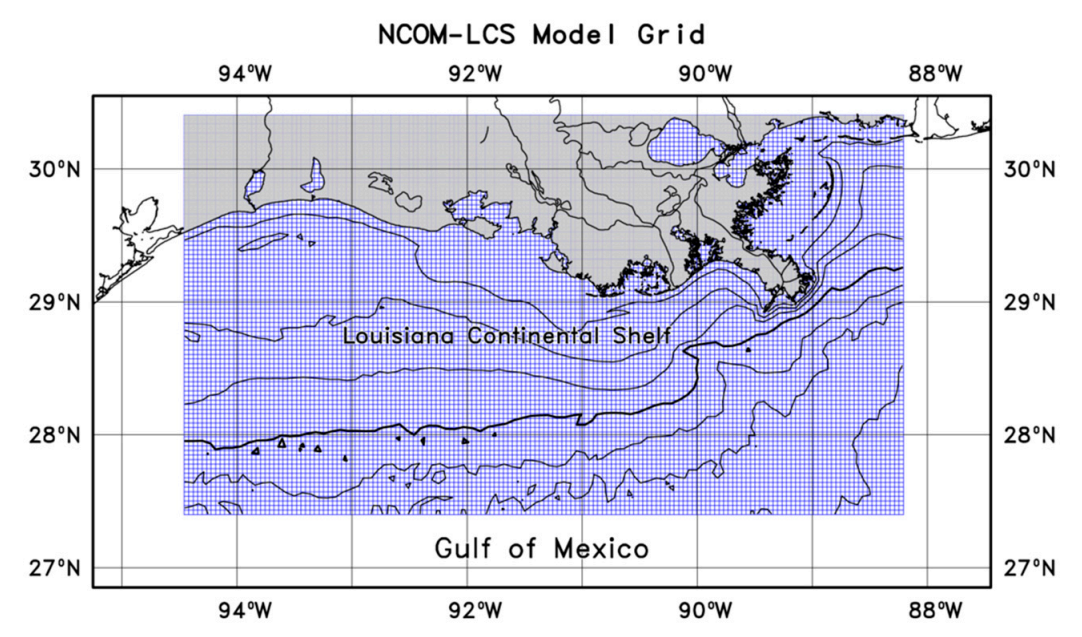

Figure 1. NCOM-LCS model domain and grid (every second gridline shown). The model ocean topography is contoured.

The model ocean topography (Figure 1) is derived from NRL global Digital Bathymetry Data Base 2-min (DBDB2) [19] and refined with National Oceanic and Atmospheric Administration (NOAA) National Geophysical Data Center (NGDC) bathymetry data from hydrographic surveys [20]. The model ocean topography is truncated to a maximum depth of $2200 \mathrm{~m}$ and the minimum water depth is set to $5 \mathrm{~m}$.

\subsection{Initial and Open Boundary Conditions}

Model initial conditions and boundary conditions (BCs) at open boundaries were obtained from the IASNFS. IASNFS provides NCOM-LCS with sea surface height $(\eta)$, temperature $(T)$, salinity $(S)$, and currents $(u$ and $v)$ for BCs. We applied satellite altimetry derived tidal forcing from the Oregon 
State University tidal database [21]. Tides $\left(\mathrm{K}_{1}, \mathrm{O}_{1}, \mathrm{P}_{1}, \mathrm{Q}_{1}, \mathrm{M}_{2}, \mathrm{~S}_{2}, \mathrm{~K}_{2}\right.$, and $\left.\mathrm{N}_{2}\right)$ are applied to model depth-averaged normal velocity, $u$, at open boundaries by combining forcing from IASNFS with a forced radiation BC modified from [22]:

$$
u=\left(u_{I A S}+u_{T}\right) \pm c\left[\left(\eta_{I A S}+\eta_{T}\right)-\eta\right] / h
$$

where $c$ is the barotropic wave phase speed: $c=\sqrt{g h}$, with $g$ being the gravitational constant and $h$ the water depth. The subscripts IAS and T denote variables from IASNFS and tidal model, respectively. The advection BC of first-order-upstream scheme was utilized for the tangential velocity, $T$ and $S$. A relaxation to the $T$ and $S$ fields of the IASNFS was applied along the open boundary over 15 model grids, or about the baroclinic deformation radius on the LCS, with a linear weighting, which increases from interior toward the boundary. The normal baroclinic velocity at the open boundary was computed using the model's full velocity equation, except that advection was only computed normal to the boundary with first-order-upwind scheme.

\subsection{River Runoff}

River runoff has a strong impact on coastal salinity, circulation and nutrient distribution. Two large rivers, the Mississippi River and Atchafalaya River discharge on average 14,800 $\mathrm{m}^{3} / \mathrm{s}$ and $6350 \mathrm{~m}^{3} / \mathrm{s}$ of water into NCOM-LCS domain, respectively. In all, discharge from 95 rivers and streams in the northern Gulf of Mexico are included in the model. Rivers are input into the ocean model as a volume source with specified salinity, temperature and vertical flow distributions. The real-time daily river flow data from the Army Corps of Engineers [23] for the Mississippi River and the Atchafalaya River (Figure 2) and from the US Geological Survey (USGS) [24] for other rivers in the model domain were used.
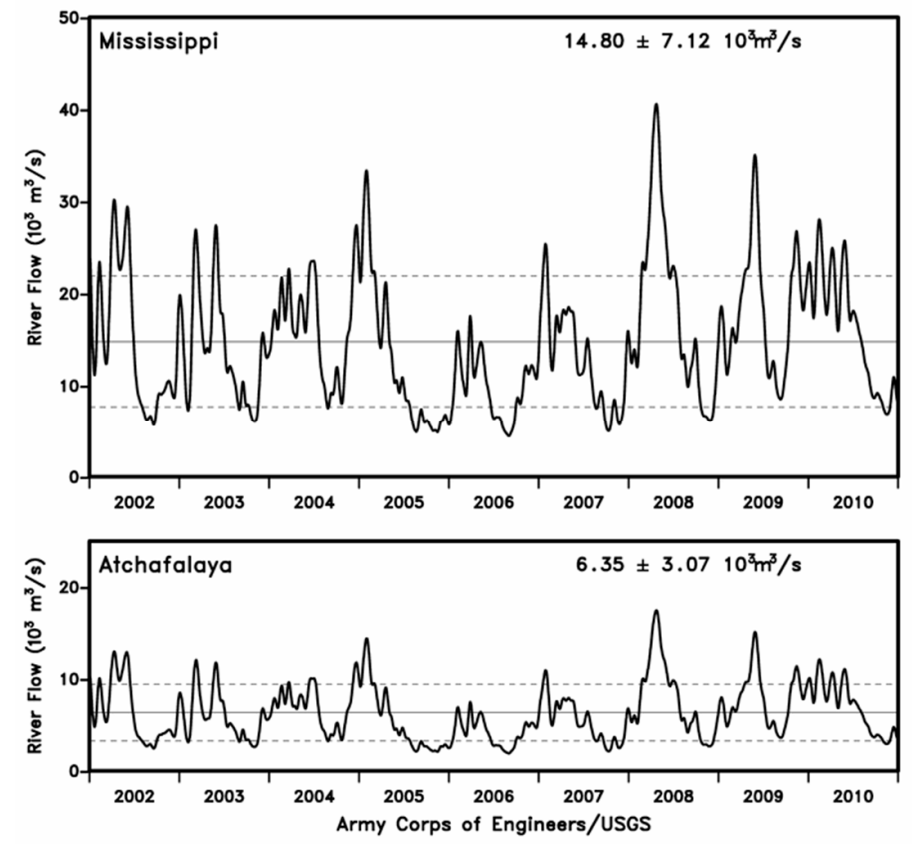

Figure 2. Real-time daily average river flows from Army Corps of Engineers for Mississippi River at Tarbert Landing, Mississippi, and for Atchafalaya River at Simmesport, Louisiana.

Atchafalaya discharge was routed to the model domain at Lower Atchafalaya (55\%) and Wax Lake outlets (45\%) and nearby smaller streams and outlets. Mississippi River discharge was routed to the model domain through Birdsfoot delta distributary channels by the following percentages: Southwest Pass (27.0\%), South Pass (11.2\%), Cubits Gap (11.1\%), Pass A Loutre (10.2), Baptiste Collette Bayou (9.8\%), Grand and Tiger Pass (9.4\%) and West Bay Diversion (4.1\%) estimated from 
the often incomplete measurements at downstream stations near the river mouths. The balance of the Mississippi River runoff was distributed among nearby smaller streams and outlets. These discharge distribution percentages were similar to those used by Rego et al. [25], although there were some notable differences between their model and ours. For example, they assigned $37 \%$ to Southwest Pass and $17 \%$ to South Pass. Differences in the location and amount of discharge to the Gulf can change the delivery of freshwater to the model domain and may affect modeled patterns of salinity and freshwater constituents on the shelf [25]. The impact of lower river distribution uncertainty on modeled hypoxia uncertainty has not been evaluated, but is of interest for future study for both improving models and evaluating the effects of existing and potential river diversions that are implemented to restore Louisiana's subsiding and eroding deltaic wetlands.

\subsection{Data Assimilation}

To better capture the variations such as from Loop Current Eddies off the outer shelf the satellite altimeter measurement was assimilated. Satellite altimeter sea surface height (SSH) from TOPEX/Poseidon, ERS-2, Geosat Follow-On (GFO), Jason-1, Envisat, Jason-2 and Cryosat-2 and multi-channel sea surface temperature (MCSST) from AVHRR were used for the data assimilation. The Modular Ocean Data Assimilation System (MODAS) [26,27] was used to produce the three-dimensional ocean temperature using correlation between SSH/MCSST and subsurface temperature. The salinity was estimated from Temperature-Salinity correlation (T-S correlation). NCOM-LCS then assimilated the analyses by continuous modification of model temperature and salinity toward the analyses applying a vertical weighting function combined with scale separation. The details of data analysis and data assimilation used are described in Ko and Wang [18]. Data assimilation, however, has a minimum impact on this study of shelf region due to application of a vertical weighting, which is very small for the shallow water [18].

\subsection{Atmospheric Forcing}

The atmospheric forcing for the model simulations utilized products from the Navy Operational Global Atmospheric Prediction System (NOGAPS) [28] and the Coupled Ocean/Atmosphere Mesoscale Prediction System (COAMPS) [29]. It consists of fields of sea level air pressure, 10-m wind from COAMPS and solar radiation and surface total heat flux from NOGAPS. The three hourly products, combination of analyses at 00:00 and 12:00 UTC and forecasts at $3 \mathrm{~h}, 6 \mathrm{~h}$ and $9 \mathrm{~h}$, were used.

Solar radiation was applied separately from the surface heat flux since solar radiation penetrates below the ocean's surface and impacts vertical mixing and sub-surface temperature. For the twin experiment, the reference run applied a constant, spatially-uniform Jerlov oligotrophic oceanic water type IA for solar penetration [5]. An adjustment of the rest of surface heat flux (solar radiation removed) was applied proportional to the difference between the multi-channel sea surface temperature (MCSST) analysis and the model sea surface temperature (SST). The surface salinity flux in the reference run was computed based on the difference between the MODAS surface salinity analysis and the model sea surface salinity (SSS) [18]. The MODAS salinity analysis is based on the T-S correlation using monthly climatology as a first guess. The salinity analysis on the surface is mostly the monthly climatology because the T-S correlation is very weak near the sea surface.

\section{Simplified Dissolved Oxygen (SDO) Model}

A simple oxygen model described by [4,30-32] was used to assess the impact of $\mathrm{Kd}$ and rainfall from satellites on the bottom water hypoxia. This simple oxygen model consists of a parameterization for air-sea oxygen exchange of Wanninkhof [30], an empirically derived parameterization of net water column respiration based on observations by Murrel et al. [31], and an empirical oxygen- and temperature-dependent parameterization of sediment oxygen consumption or SOC described by Hetland and DiMarco [32]. The net water column respiration term is constant in time and in depth, but varies horizontally with water depth. Inshore of the 20-m isobath, net water column respiration is 
negative implying an oxygen source; the largest positive net water column respiration representing an oxygen sink occurs between the 20 - and 30-m isobaths [4].

Oxygen initial condition and boundary condition are based on the NOAA National Ocean Data Center (NODC) World Ocean Atlas. For the air-sea oxygen exchange the COAMPS wind that is used to drive NCOM-LCS was used. The fully three-dimensional evolution of dissolved oxygen is also subjected to advection and mixing driving by the NCOM-LCS produced currents and mixing coefficients.

\section{Satellite Measurements}

As mentioned in Section 2.5, for the reference model run, a uniform Jerlov oligotrophic oceanic water type IA was specified for solar penetration. Applying a uniform water type is sufficient for most ocean regions, particularly in deep water. However, in coastal areas, higher absorption coefficients in river plume and inshore regions are generally observed, due to higher concentrations of chlorophyll, CDOM, and suspended particulate matter. As such, this approach neglects the spatial and temporal variability in the solar attenuation, which can lead to overheating near the bottom in shallow waters due to incorrect, excessive solar penetration in the model, e.g., [33]. To account for this variability in water column absorption, we explore an alternative approach to attenuate solar radiation through the water column, using ocean color satellite imagery (MODIS-Aqua).

The approach to estimate surface salinity flux for the reference model run is described in Section 2.5. It basically uses monthly climatology data from MODAS, which can be a significant drawback as it excludes inter-annual variability. Thus, we explore an alternative approach to estimate surface salinity flux using satellite rainfall data (TRMM). The MODIS and TRMM data are used in the "test" model run described in the analyses and results below.

\subsection{Diffuse Attenuation Coefficient from MODIS}

Diffuse Sunlight that penetrates into the water column interacts with dissolved and particulate material in the surface layer. Through absorption and scattering processes, the spectral quality of the light is altered before it is reflected back out and recorded by satellite ocean color sensors. Following atmospheric correction of the top-of-the-atmosphere radiance measurements, an estimate of spectral water-leaving radiance is obtained, which can be used to calculate the diffuse attenuation coefficient of downwelling irradiance $(\mathrm{Kd})$ [34]. $\mathrm{Kd}$ is an indication of how deep the solar radiation can penetrate into the water column; the more dissolved and particulate matter in the water, the higher the Kd value, and the less light will be able to penetrate (i.e., shallower penetration). Thus, the satellite imagery provides a spatially-varying synoptic estimate of the vertical attenuation of light in the water.

MODIS imagery was processed through the Naval Research Laboratory Automated Processing System (APS) [35] to create monthly composite images of $\mathrm{Kd}$ at $488 \mathrm{~nm}(\mathrm{Kd}(488))$ at $1 \mathrm{~km}$ resolution for the study domain and time period, using the Kd algorithm of [36]. APS is consistent with atmospheric correction and bio-optical algorithms implemented in NASA SeaDAS image processing software. As an example, Figure 3 shows MODIS Kd (488) over the model domain, for 4 months in 2006.

$\mathrm{Kd}$ (488) was subsequently converted to Kd for photosynthetically available radiation (PAR, covering 400-700 nm spectral interval), denoted $K_{P A R}$, based on empirical algorithms for the LCS [37]. $K_{\text {PAR }}$ were interpolated spatially to the model grid and used as input to the NCOM-LCS model in the "test" run to determine the penetration depth of solar radiation applying a logarithm scheme. Monthly composites are used, as opposed to daily images, to reduce the number of missing pixel values due to cloud blockage. Temporal interpolation was performed at each model time step. 

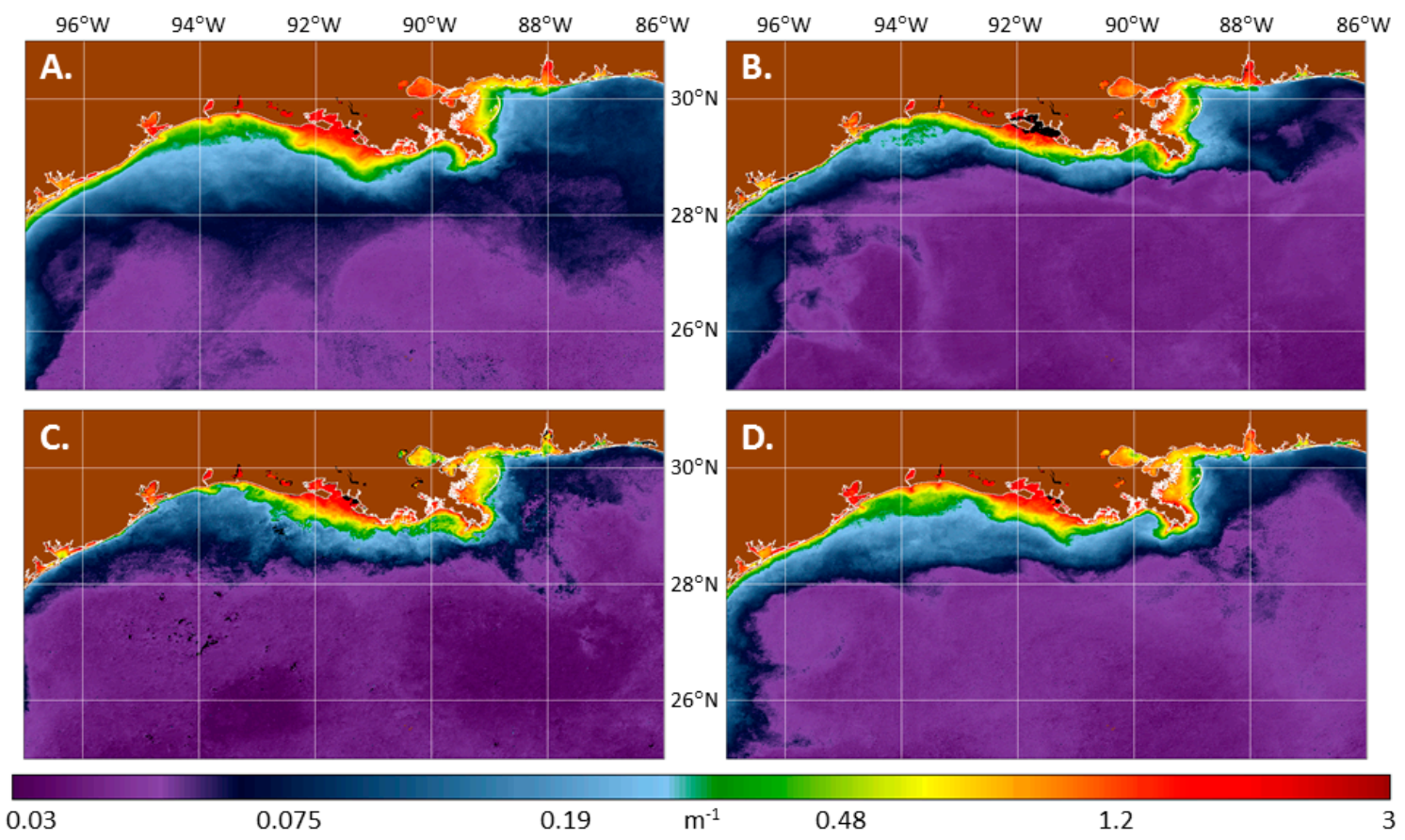

Figure 3. Moderate Resolution Imaging Spectroradiometer (MODIS) Kd (488), 2006. (A) January; (B) April; (C) July; (D) October. Color scale units are $\mathrm{m}^{-1}$.

\subsection{Rainfall from TRMM}

Spaceborne radars and passive microwave radiometers, such as the Tropical Rainfall Measurement Mission's (TRMM) Precipitation Radar (PR) and Microwave Imager (TMI), can provide information on integrated column precipitation content, areal distribution, and intensity. Rainfall accumulation data covering the NCOM-LCS model domain and time period were obtained from the TRMM Online Visualization and Analysis System (TOVAS) web site [38]. We used the 3B43 V7 data product, with horizontal resolution of $0.25^{\circ}$ and temporal resolution of one month. This product was developed to provide best-estimate precipitation rates from TRMM and other data sources (such as rain gauges, Advanced Microwave Scanning Radiometer for Earth Observing Systems (AMSR-E), Special Sensor Microwave Imager (SSMI), and others) [39]. Figure 4 shows example rainfall distributions for 4 months in 2006. Interannual monthly rainfall variability, averaged over the entire model domain $\left(27.0^{\circ} \mathrm{N}-30.5^{\circ} \mathrm{N}, 88^{\circ} \mathrm{W}-94.5^{\circ} \mathrm{W}\right)$, is shown in Figure 5. TRMM rainfall was spatially interpolated to the model grid. Surface salinity flux for the NCOM-LCS "test" run was then calculated as the difference between precipitation (the TRMM rainfall) and evaporation (derived from NOGAPS latent heat flux) and applied to the model surface layer. Temporal interpolation was performed at each model time step. 


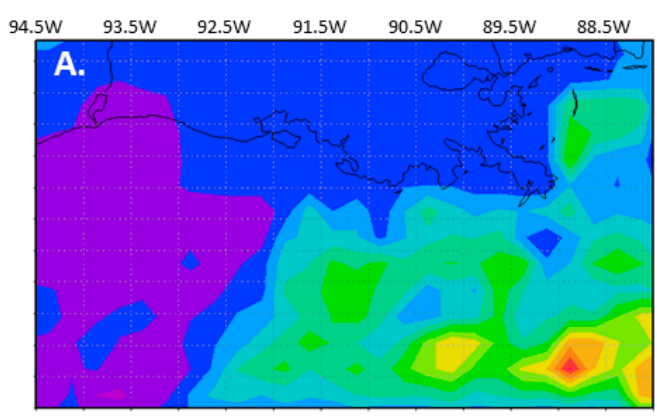

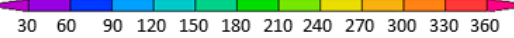

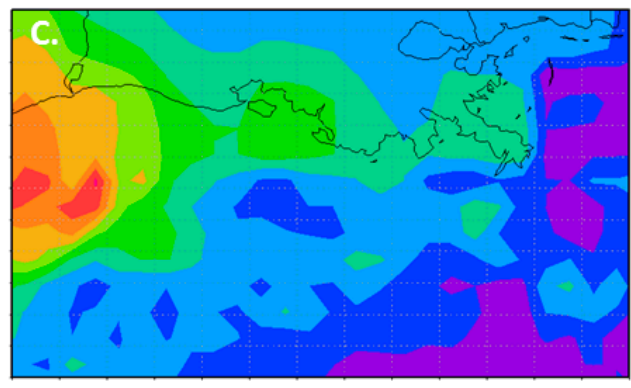

$\begin{array}{llllllllll}50 & 100 & 150 & 200 & 250 & 300 & 350 & 400 & 450 & 500\end{array}$

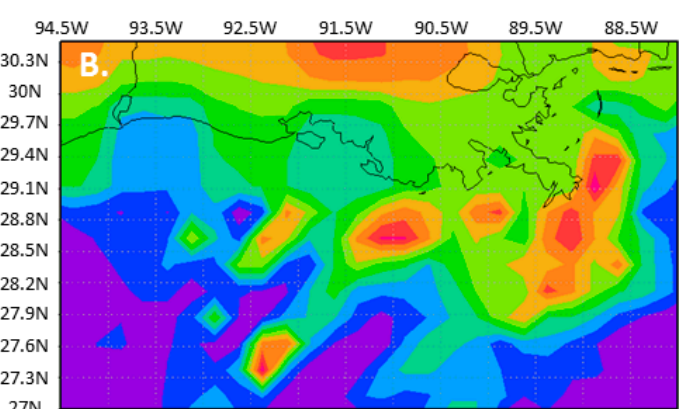

$\begin{array}{llllllllll}0 & 20 & 40 & 60 & 80 & 100 & 120 & 140 & 160 & 180\end{array}$

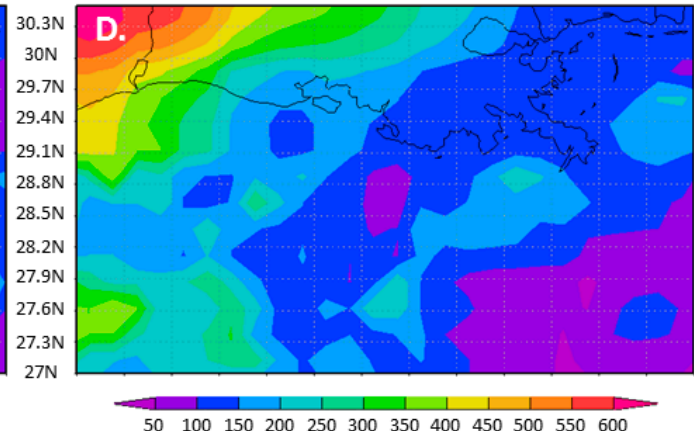

50100150200250300350400450500550600

Figure 4. Tropical Rainfall Measurement Mission (TRMM) accumulated monthly rainfall, 2006. (A) January; (B) April; (C) July; (D) October. Note color scale changes for each panel, units are mm.

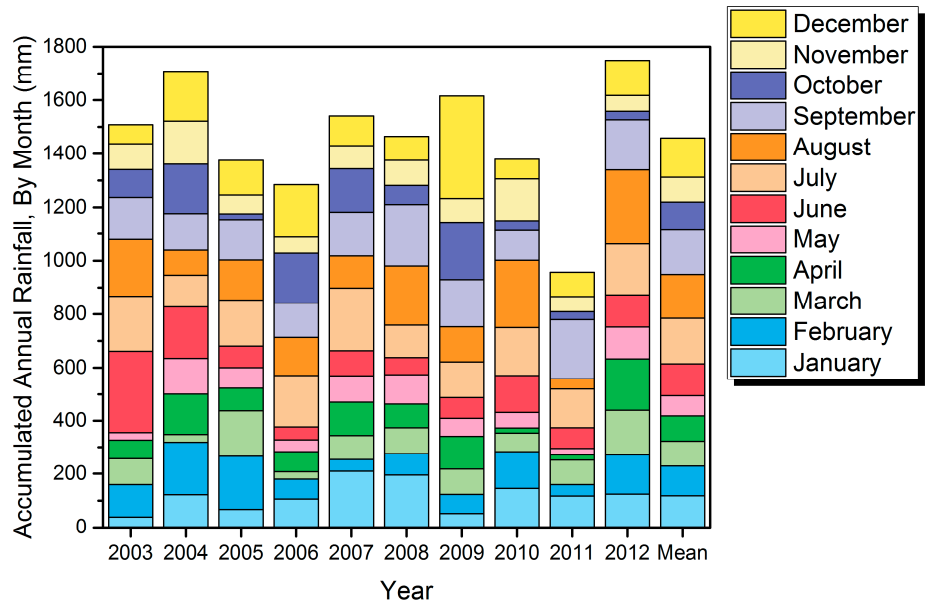

Figure 5. Monthly accumulated rainfall, averaged over the model domain, 2003-2012.

\section{Results of Twin Experiment}

The twin experiment was conducted applying NCOM-LCS for the period from 2002 to 2010 when there are observations available for comparisons. The model time step is rather small at $150 \mathrm{~s}$ but the model variables were outputted every hour. The reference case was conducted without satellite data and with a constant and spatially/temporally-uniform Kd based on the Jerlov Type 1A oligotrophic water and the surface salinity flux was estimated from the difference between model SSS and MODAS SSS which is essentially the monthly climatology. The test case was conducted with satellite data, which includes the spatially-varying monthly Kd estimated from MODIS ocean color images and the surface salinity flux estimated with TRMM rainfall. Otherwise, all other forcing such as wind, heat fluxes including solar radiation, river runoff, and BCs from IASNFS were identical as described in the previous sections. The hypoxia simulations based on the SDO (Section 3) were conducted sequentially by applying the NCOM-LCS outputs from the twin experiment. 
The observations of temperature and salinity from shelf-wide cruises conducted by the US Environmental Protection Agency (EPA) [31,40] on the Louisiana shelf were used for ocean model evaluation. Data from a total of 706 CTD stations occupied from December 2002 to August 2007 are available. The observation-based estimate of hypoxic area on the Louisiana shelf from an annually recurring mid-summer mapping cruise $[6,41]$ were used for evaluation of hypoxia prediction.

\subsection{Impact on Ocean Model Predictions}

Figure 6 shows the comparisons between observed and modeled salinity and temperature (averaged along each offshore transect; see [3] for station locations), with and without the satellite data. Root-mean-squared errors (RMSE) are also calculated. For the integrated values, the temperature (Figure 6, right column) was fairly well predicted even without the satellite data with $0.7^{\circ} \mathrm{C}$ RMSE overall (Figure 6, right-top panel). With satellite data the model prediction did improve and RMSE decreased to $0.55^{\circ} \mathrm{C}$ with a tighter correlation with observations (Figure 6, right-bottom panel) (Table 1). The temperature profiles predicted from the twin experiment as shown along a cross-section at $91.5^{\circ} \mathrm{W}$ (Figure 7), however, demonstrate the significant impact of satellite data. The overheating near the bottom in the nearshore water (Figure 7a) was largely removed once the satellite Kd was applied (Figure $7 b$ ). The spatially/temporally-varying Kd from MODIS effectively prevented over-penetration of solar radiation and improved the nearshore vertical thermal structure.
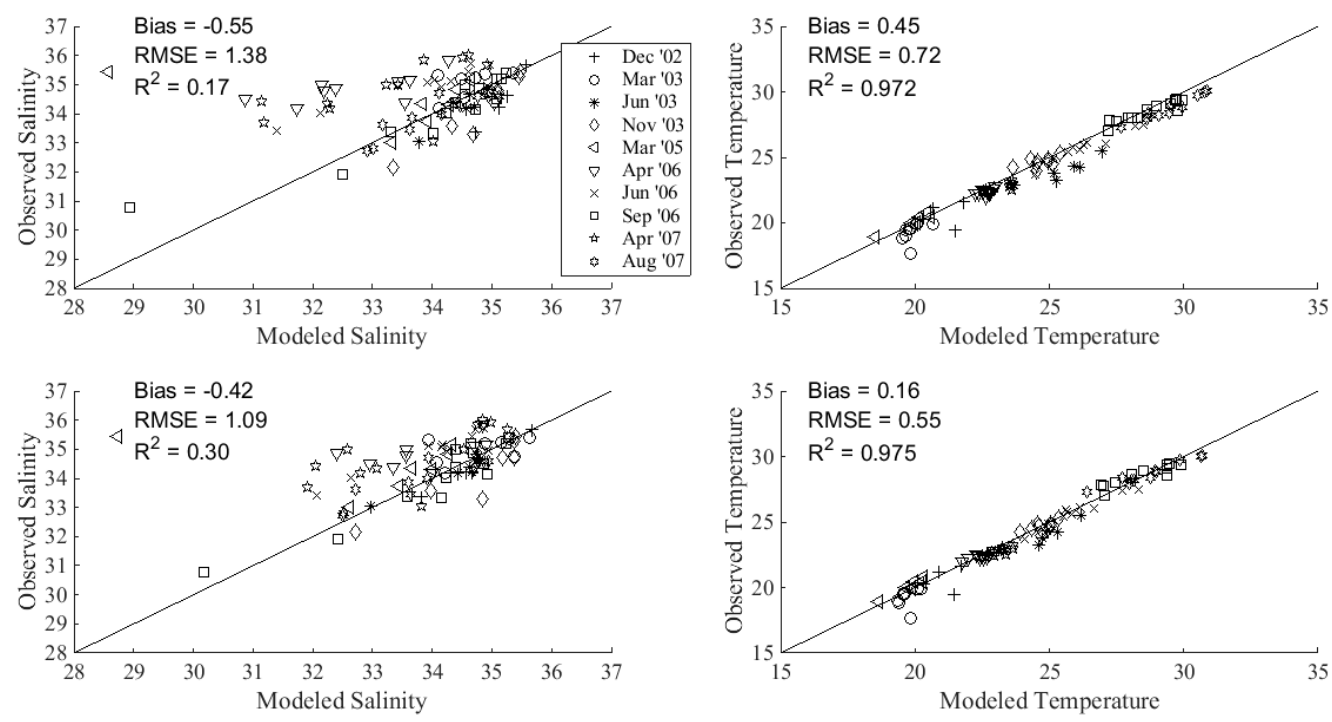

Figure 6. Comparison of mean transect salinity and temperature from observations during 12 cruises from 2 December 2002 to 7 August 2007 and corresponding values from models without (upper plots) and with (lower plots) satellite-derived $\mathrm{Kd}$ and rainfall. The legend shows the dates of cruises. In the lower plots, smaller mean bias $\left(\frac{1}{n} \cdot \sum_{i=1}^{n}\right.$ Model $_{i}-$ Observed $\left._{i}\right)$ and root mean square error (RMSE) and larger coefficient of determination $\left(R^{2}\right)$ were obtained using satellite data. The lines represent the $1: 1$ line.

Table 1. Comparison of mean transect temperature from observations and corresponding values from model without (reference case) and with (test case) satellite-derived $\mathrm{Kd}$ and rainfall. Unit for bias and root mean square error (RMSE) are ${ }^{\circ} \mathrm{C}$.

\begin{tabular}{ccc}
\hline Temperature & Reference Case & Test Case \\
\hline Bias & 0.45 & 0.16 \\
RMSE & 0.72 & 0.55 \\
$\boldsymbol{R}^{2}$ & 0.972 & 0.975 \\
\hline
\end{tabular}




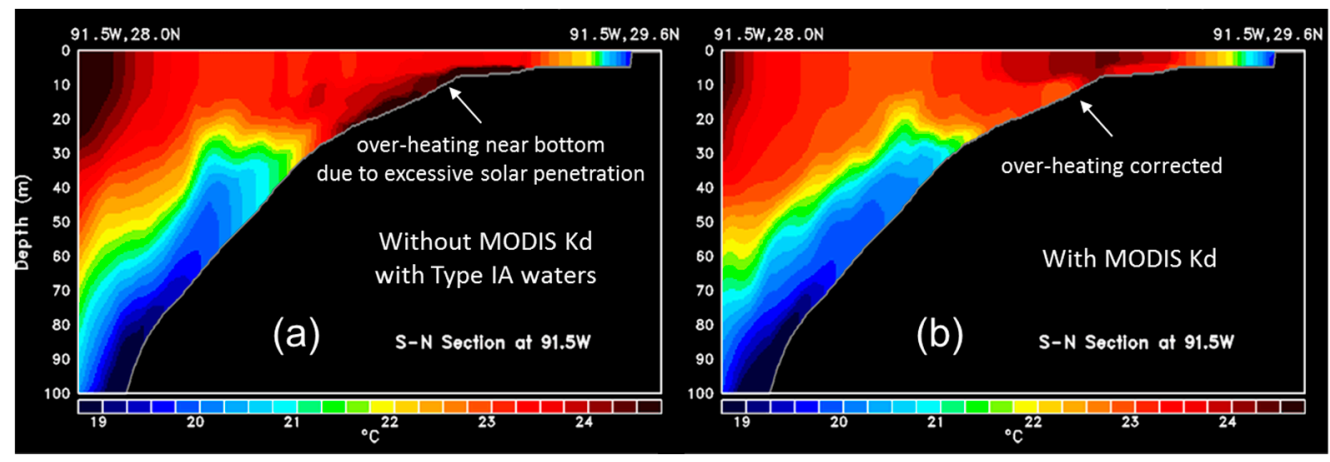

Figure 7. Effect of including satellite diffuse attenuation coefficient $(\mathrm{Kd})$ on thermal structure. Temperature north-south cross-section (right to left) at $91.5^{\circ} \mathrm{W}$ for May 2008 for (a) reference run (solar attenuation parameterized as Jerlov Type 1A oligotrophic water); and for (b) test run (solar attenuation determined from satellite $\mathrm{Kd}$ ).

In a model inter-comparison study, Fennel et al. [42] shows the NCOM-LCS applying the Kd from MODIS produced colder bottom water on the Louisiana shelf than other two models that used constant and uniform Kd. The colder bottom water in NCOM-LCS is due to reduced solar penetration in the nearshore murky water which leads to a much lower bias evaluated against the observations than other two models, again demonstrating the importance of applying spatially/temporally varying satellite Kd on the overall model temperature prediction.

Salinity predictions are also improved when satellite data are included, with RMSE between the observations and model values decreasing from 1.38 to 1.09 (Figure 6, left column) (Table 2). The impact of applying surface salinity flux estimated with TRMM rainfall is further demonstrated in the salinity profiles along a cross-section at $90^{\circ} \mathrm{W}$ across the shelf (Figure 8). The water nearshore is fresher and offshore saltier (Figure $8 \mathrm{~b}$ ) with TRMM rainfall included, compared to the reference case (Figure 8a). Without the TRMM rainfall, we observed lower correlation $\left(R^{2}=0.17\right)$ between the model predictions and the observations. Particularly, during 2006, the salinity predictions were much fresher than the observed (Figure 6, left-top panel). This is because 2006 was a dry year, as indicated by less rainfall over much of the model domain relative to other years in the modeling time period (Figure 5) and less river discharge (Figure 2). Using monthly salinity climatology to calculate surface salinity flux (as in the reference case) resulted in over-estimation of salinity flux and lower modeled salinity values compared to observations. Applying temporally and spatially varying TRMM rainfall improved the salinity prediction overall (Figure 6, left-bottom panel) and the over-estimation of fresh water during the 2006 dry season was much reduced.

With improved prediction in both temperature and salinity resulting from the inclusion of the satellite data, the overall water column stratification on the shelf improved. The distribution of the maximum buoyancy frequency (N) (Figure 9) at various locations on the shelf shows the stratifications were strengthened, becoming closer to the observations. The improved stratification has a strong impact on the extent of the bottom water hypoxia as discussed in the next session.

Table 2. Comparison of mean transect salinity from observations and corresponding values from model without (reference case) and with (test case) satellite-derived $\mathrm{Kd}$ and rainfall. Unit for bias and RMSE are ppt.

\begin{tabular}{ccc}
\hline Salinity & Reference Case & Test Case \\
\hline Bias & -0.55 & -0.42 \\
RMSE & 1.38 & 1.09 \\
$\boldsymbol{R}^{2}$ & 0.17 & 0.30 \\
\hline
\end{tabular}




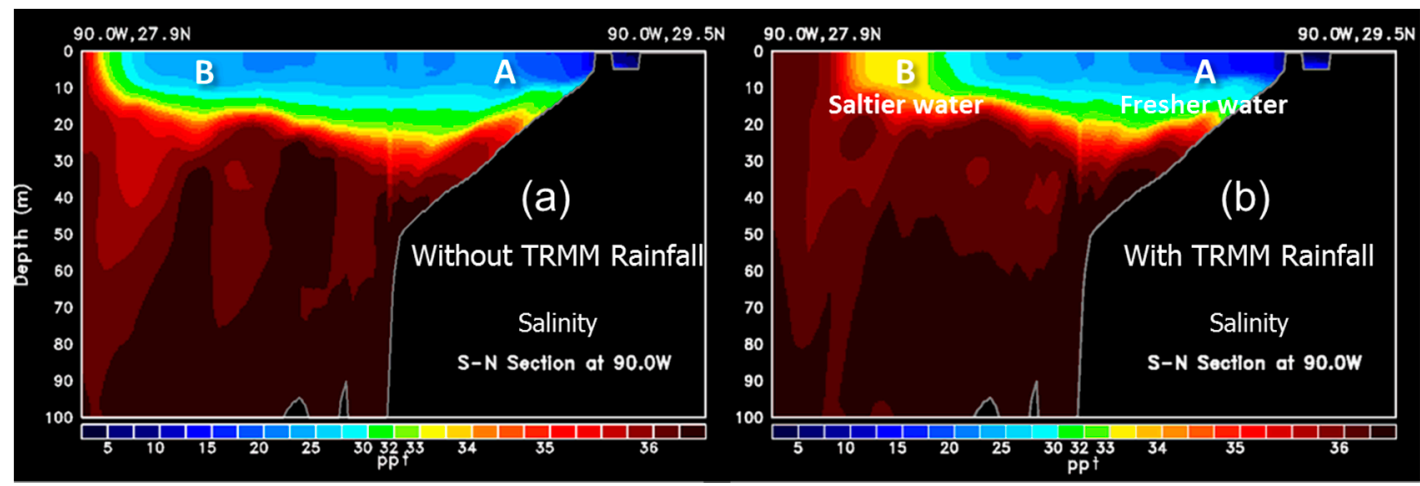

Figure 8. Effect of including satellite TRMM rainfall on salinity. Salinity north-south cross-section (right to left) at $90^{\circ} \mathrm{W}$ for May 2008 for (a) reference run (monthly climatology surface salinity flux); and for (b) test run (salinity flux estimated with TRMM rainfall).
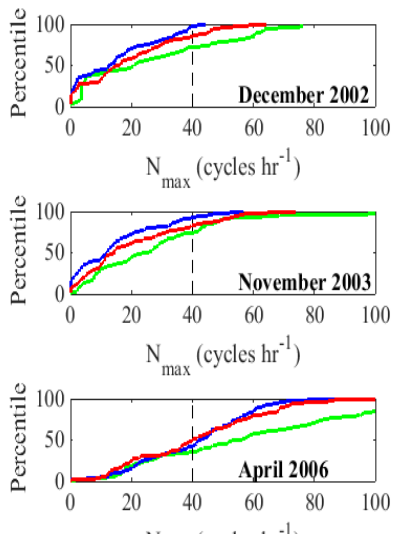

$\mathrm{N}_{\max }\left(\right.$ cycles hr $\left.^{-1}\right)$
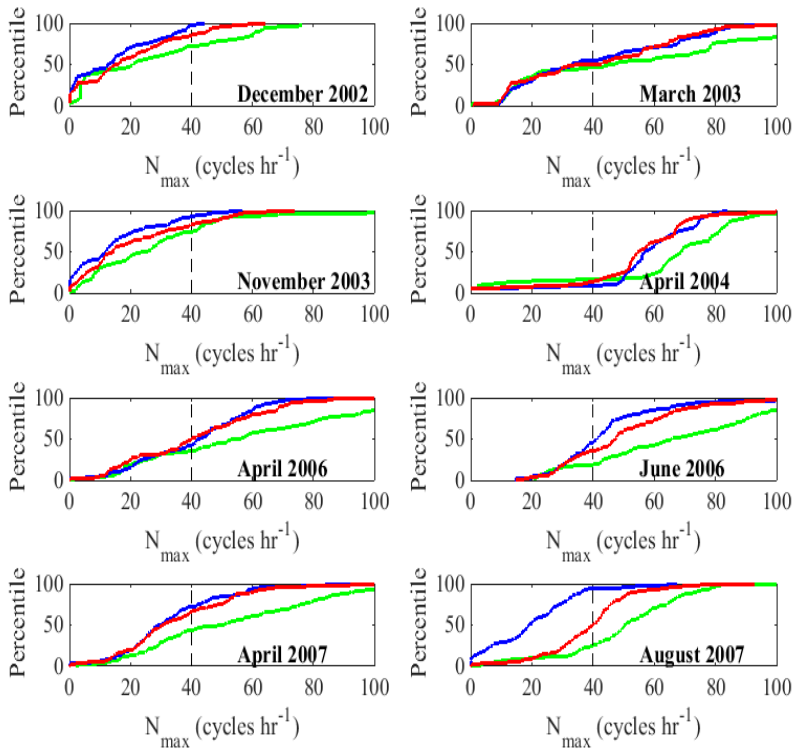

$\mathrm{N}_{\max }\left(\right.$ cycles hr $\left.{ }^{-1}\right)$

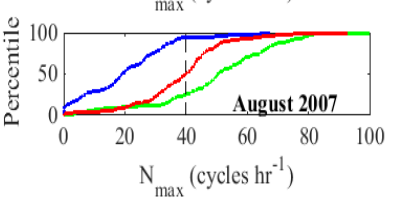

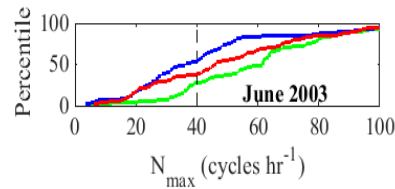
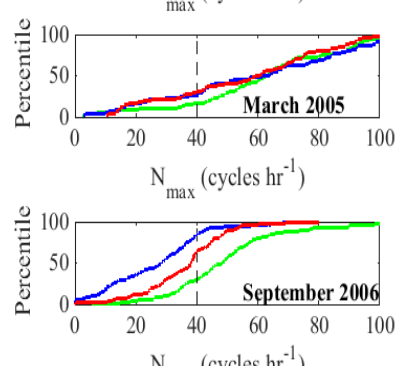

$\mathrm{N}_{\max }\left(\right.$ cycles hr $\left.{ }^{-1}\right)$

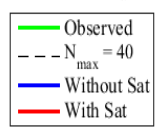

Figure 9. Cumulative distribution function of maximum buoyancy frequency $\left(\mathrm{N}_{\max }\right)$, which is an index of the strength of vertical stratifications, for 12 cruises (20-90 stations occupied per cruise from December 2002 to August 2007. Observations (green) were compared to a reference model run without satellite data (blue) and a test model run with satellite data (red). The black dashed vertical line at $\mathrm{N}=40$ represents the buoyancy frequency at which hypoxia begins to occur [7].

\subsection{Impact on Bottom Hypoxia}

The hypoxia model based on SDO described in Section 3 was applied to estimate the dissolved oxygen concentration over the entire NCOM-LCS domain from 2002 to 2010 applying ocean predictions (temperature, salinity, current and mixing coefficient) from the twin experiment. The area of bottom water hypoxia was calculated across the grid as the area where the bottom layer oxygen concentration was less than $64 \mathrm{mmol} / \mathrm{m}^{3}$. Figure 10 shows the time series of the simulated bottom hypoxia area on the Louisiana shelf. The blue curve indicates the reference case and the red curve the test case with satellite data. The area of bottom hypoxia has a strong seasonal variation with the largest hypoxic area observed during the summer season due to the decay of the phytoplankton bloom following large spring river nutrient runoff, e.g., Lohrenz et al. [43] and increasing light levels. But it is also due to increased water column stratification $[7,44]$ and to changes in summer time current direction from westward down coast to eastward up coast, which increases the nutrient retention time on the shelf [3]. 
Interannual variation is also evident related to differences in yearly river runoff and physical conditions in ocean such as temperature, salinity and current and in atmosphere such as wind and solar radiation.

Including satellite data in the model simulations has a substantial impact on the predicted bottom hypoxia. On average, the area of bottom hypoxia on the shelf almost doubled for the test case (inclusion of satellite data, Figure 10). The stronger stratification due to the improved temperature and salinity prediction with satellite data reduces the vertical mixing and constrains the exchange of oxygen with the surface layer; therefore the oxygen concentration in the bottom layer decreases and the area of bottom hypoxia increases. In the SDO model, the lower bottom water temperature in the test case also results in lower microbial oxygen consumption. However, owing to the stronger stratification in the test case, the smaller oxygen consumption rate is sufficient to drawdown oxygen to hypoxic levels. The year to year comparison of the predicted bottom water hypoxia area, calculated from model grids where low dissolved oxygen $\left(<64 \mathrm{mmol} / \mathrm{m}^{3}\right)$ persisted over 15 days each season, indicates that it is overall much more comparable to the estimation based on the cruise observations $[6,41]$ when satellite data are included in the model (Figure 11). There are inconsistencies. For example, we are uncertain as why in the test case the model predicted a rather large hypoxia area in 2009 relative to the observation. We do not have CTD measurements for that year to make a close exam. Otherwise, the observed hypoxia area was based on a single week-long cruise, the observation may not be representative, e.g., hypoxia may occur outside of cruise duration, therefore area of hypoxia may be underestimated for that year.

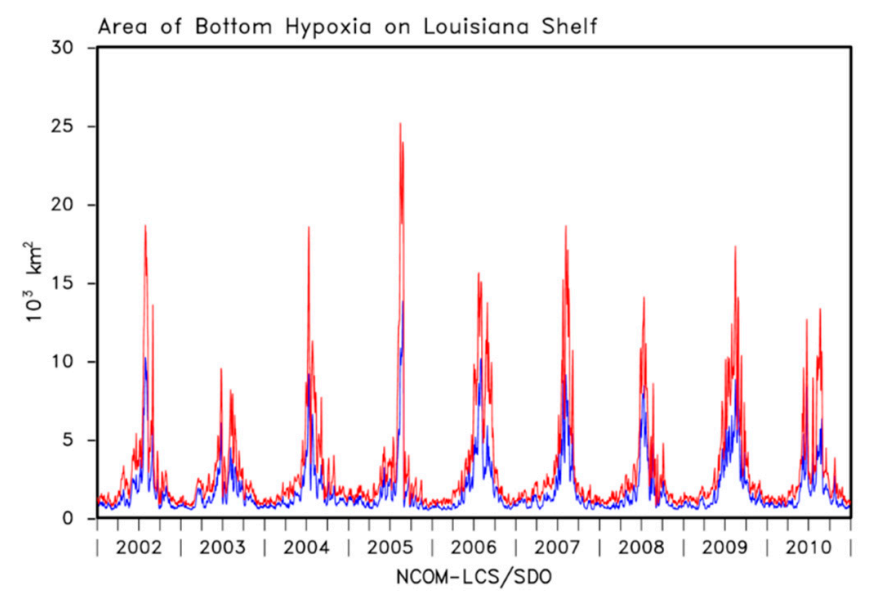

Figure 10. Area of bottom hypoxia on the Louisiana shelf simulated with Simplified Dissolved Oxygen (SDO) parameterization applying model physical parameters without satellite data (blue) and with satellite data (red).

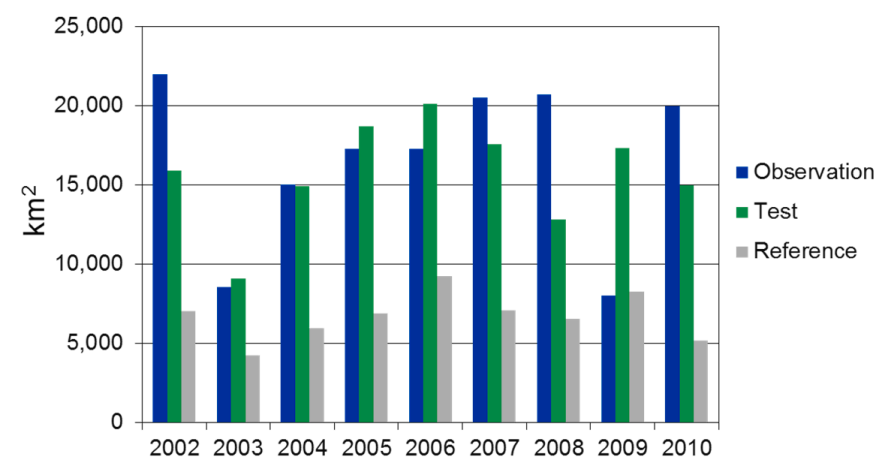

Figure 11. Area of bottom hypoxia on the Louisiana Shelf: blue from observation, green from the test case with satellite data and grey from the reference case without satellite data. For the model, the hypoxic area was estimated as the area where the hypoxic condition $\left(\mathrm{DO}<64 \mathrm{mmol} / \mathrm{m}^{3}\right)$ persisted over 15 days each season. 


\section{Conclusions}

To assess the impact of satellite remote sensing data on simulations of coastal circulation and hypoxia on the Louisiana continental shelf, a twin experiment with and without satellite data was conducted for the 2002-2010 time period. The coastal ocean model (NCOM-LCS) was employed. The NCOM-LCS covers the entire Louisiana shelf where the extensive bottom hypoxia occurs yearly during the summer season. This provides a good opportunity to assess the impact of satellite data on the simulation of hypoxia.

The temporally/spatially varying Kd derived from MODIS and rainfall from TRMM were used in the twin experiment. The reference case used constant light penetration of Jerlov Type 1A oligotrophic water, which is typical for the open ocean, but leads to excessive solar penetration in nearshore waters and over-heating near the bottom. Also, for the reference case, applying seasonal climatology to estimate the surface salinity flux precluded any interannual variation in the salinity prediction. With the satellite data, the Kd from MODIS and rainfall from TRMM, the ocean model prediction was much improved. The over-heating near bottom was corrected and over-estimation of the fresh water during a dry year (2006) was reduced. The improved temperature and salinity prediction led to improved model stratification.

The hypoxia simulation was conducted using the ocean model outputs from the twin experiment and a simple dissolved oxygen (SDO) model. The simulated annually-integrated hypoxic area increased substantially for each model year when satellite data were included, and agreement with observations improved.

The complexity of modeling the circulation at the Louisiana shelf was illustrated by e.g., Hetland and DiMarco [14]. Various factors that may produce uncertainties in the modeling of circulation and hypoxia on LCS were investigated by Mattern et al. [11]. In this study, we examined the effects of Kd and rainfall data from satellite on the modeling applying a twin experiment. Overall improvement in the model circulation and hypoxia simulation with satellite data clearly demonstrates the impact of the satellite remote sensing data from MODIS and TRMM on modeling the Louisiana shelf.

Acknowledgments: This work was supported by an inter-agency agreement between the US EPA and the Naval Research Laboratory. Analyses and visualizations used in Figure 4 of this paper were produced with the Giovanni online data system, developed and maintained by the NASA GES DISC. We also acknowledge the TRMM mission scientists and associated NASA personnel for the production of the rainfall data used in this research effort. We thank for the useful comments and suggestions from 3 reviewers. The views expressed in this manuscript are those of the authors and do not necessarily reflect the views or policies of the US Environmental Protection Agency and the Naval Research Laboratory.

Author Contributions: D.S.K. and R.W.G.J. conceived and designed the experiment; D.S.K. performed the experiment; D.S.K., R.W.G.J., B.P. and J.C.L. analyzed the data; D.S.K. and R.W.G.J. wrote the paper; J.C.L. and B.P. provided reviews and comments.

Conflicts of Interest: The authors declare no conflict of interest.

\section{Abbreviations}

The following abbreviations are used in this manuscript:

$\begin{array}{ll}\text { TRMM } & \text { Tropical Rainfall Measurement Mission } \\ \text { MODIS } & \text { Moderate Resolution Imaging Spectroradiometer } \\ \text { Kd } & \text { Diffuse attenuation coefficient } \\ \text { CADIOP } & \text { Cloud-Aerosol Lidar with Orthogonal Polarization } \\ \text { NOGAPS } & \text { Navy Operational Global Atmospheric Prediction System } \\ \text { LCS } & \text { Louisiana Continental Shelf } \\ \text { SDO } & \text { Simplified Dissolved Oxygen model } \\ \text { NRL } & \text { Naval Research Laboratory } \\ \text { NCOM } & \text { Navy Coastal Model } \\ \text { IASNFS } & \text { Intra-Americas Sea Nowcast/Forecast System } \\ \text { DBDB2 } & \text { Digital Bathymetry Data Base 2-min }\end{array}$




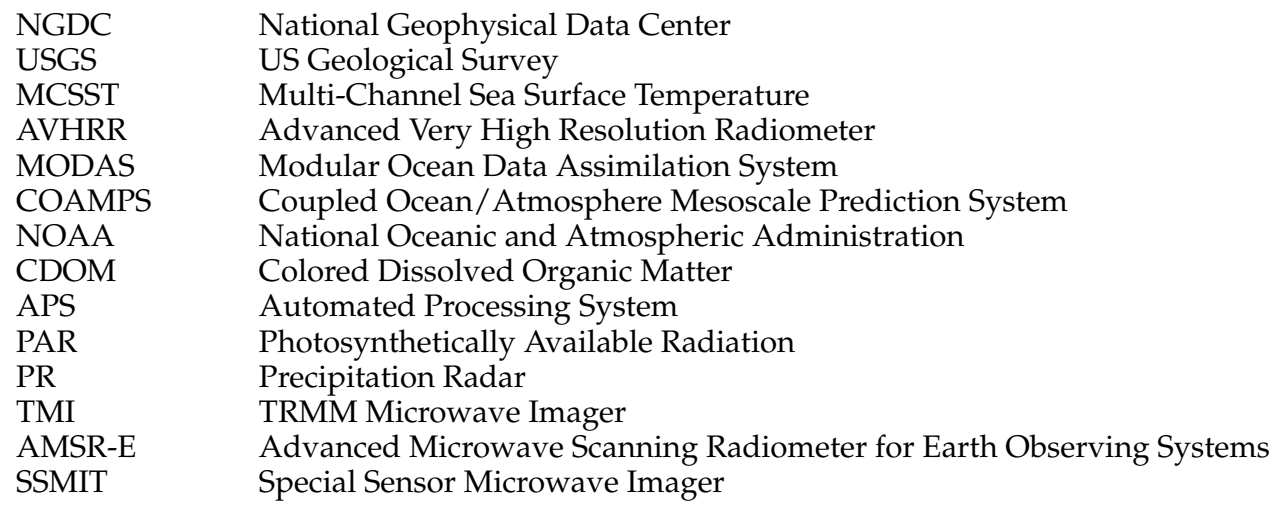

\section{References}

1. Rhodes, R.C.; Hurlburt, H.E.; Wallcraft, A.J.; Barron, C.N.; Martin, P.J.; Metzger, E.J.; Shriver, J.; Ko, D.S.; Smedstad, O.M.; Cross, S.; et al. Navy real-time global modeling system. Oceanography 2002, 15, $29-43$. [CrossRef]

2. Fennel, K.; Hetland, R.; Feng, Y.; DiMarco, S. A coupled physical-biological model of the Northern Gulf of Mexico: model description, validation, and analysis of phytoplankton variability. Biogeosciences 2011, 8 , 1881-1899. [CrossRef]

3. Lehrter, J.; Ko, D.S.; Murrell, M.; Richard, G.; James, H.; Blake, S.; Gould, R.W.; Penta, B. Nutrient transports and source/sink dynamics on the inner Louisiana continental shelf. J. Geophys. Res. 2013, 118, 4822-4838. [CrossRef]

4. Yu, L.; Fennel, K.; Laurent, A. A modeling study of physical controls on hypoxia generation in the northern Gulf of Mexico. J. Geophys. Res. 2015, 120, 5019-5039. [CrossRef]

5. Jerlov, N.G. Optical classification of ocean water. In Physical Aspects of Light in the Sea; Tyler, J.E., Ed.; U. Hawaii Press: Honolulu, HI, USA, 1964; pp. 45-49.

6. Rabalais, N.N.; Turner, R.E.; Wiseman, W.J. Gulf of Mexico hypoxia, aka "The dead zone". Ann. Rev. Ecol. Syst. 2002, 33, 235-263. [CrossRef]

7. Bianchi, T.S.; Wysocki, L.A.; Schreiner, K.M.; Filley, T.R.; Corbett, D.R.; Kolker, A.S. Sources of terrestrial organic carbon in the Mississippi plume region: evidence for the importance of coastal marsh inputs. Aquat. Geochem. 2011, 17, 431-456. [CrossRef]

8. Wiseman, W.J.; Rabalais, N.N.; Turner, R.E.; Dinnel, S.P.; MacNaughton, A. Seasonal and interannual variability within the Louisiana coastal current: Stratification and hypoxia. J. Mar. Syst. 1997, 12, 237-248. [CrossRef]

9. How is Hypoxia Mapped in the Summer? Available online: http://www.gulfhypoxia.net/Research/ Shelfwide\%20Cruises/\#Size (accessed on 19 May 2016).

10. Mississippi River Gulf of Mexico Watershed Nutrient Task Force New Goal Framework. Available online: http:/ / www.epa.gov/sites/production/files/2015-07/documents/htf-goals-framework-2015.pdf (accessed on 18 May 2016).

11. Matterm, J.P.; Fennel, K.; Dowd, M. Sensitivity and uncertainty analysis of model hypoxia estimates for the Texas-Louisiana shelf. J. Geophys. Res. Oceans 2013, 118, 1316-1332. [CrossRef]

12. Laurent, A.; Fennel, K. Simulated reduction of hypoxia in the northern Gulf of Mexico due to phosphorus limitation. Elementa 2014. [CrossRef]

13. Justić, D.; Wang, L. Assessing temporal and spatial variability of hypoxia over the inner Louisiana-upper Texas shelf: Application of an unstructured-grid three-dimensional coupled hydrodynamic-water quality model. Cont. Shelf Res. 2014, 72, 163-179. [CrossRef]

14. Hetland, R.D.; DiMarco, S.F. Skill assessment of a hydrodynamic model of circulation over the Texas-Louisiana continental shelf. Ocean. Model. 2012, 43-44, 64-76. [CrossRef]

15. Ko, D.S.; Martin, P.J.; Rowley, C.D.; Preller, R.H. A real-time coastal ocean prediction experiment for MREA04. J. Mar. Syst. 2008, 69, 17-28. [CrossRef]

16. Martin, P.J. A Description of the Navy Coastal Ocean Model Version 1.0; NRL Report NRL/FR/7322-00-9962; Naval Research Laboratory: Washington, DC, USA, 2000. 
17. Ko, D.S.; Preller, R.H.; Martin, P.J. An experimental real-time Intra-Americas Sea Ocean Nowcast/Forecast System for coastal prediction. In Proceedings of the AMS 5th Conference on Coastal Atmospheric and Oceanic Prediction and Processes, Seattle, WA, USA, 6-8 August 2003.

18. Ko, D.S.; Wang, D.P. Intra-Americas Sea Nowcast/Forecast System Ocean. Reanalysis to Support Improvement of Oil-Spill Risk Analysis in the Gulf of Mexico by Multi-Model Approach; BOEM 2014-1003. Department of the Interior, Bureau of Ocean Energy Management: Herndon, VA, USA, 2014.

19. NRL DBDB2-Global 2-Minute Topography. Available online: http://www7320.nrlssc.navy.mil/DBDB2 WWW / (accessed on 18 May 2016).

20. Bathymetry and Global Relief-Scientific Stewardship, Products, and Services for Ocean Depth Data and Derived Digital Elevation Models. Available online: http://www.ngdc.noaa.gov/mgg/bathymetry/ (accessed on 18 May 2016).

21. Egbert, G.D.; Erofeeva, S.Y. Efficient inverse modeling of barotropic ocean tides. J. Atmos. Ocean. Technol. 2003, 19, 183-204. [CrossRef]

22. Flather, R.A.; Proctor, R. Prediction of North Sea storm surges using numerical models: Recent developments in the UK. In North Sea Dynamics; Sundermann, J., Lenz, W., Eds.; Springer: New York, NY, USA, 1983; pp. 299-317.

23. The Real-Time Daily River Flow Data. Available online: http://www.mvn.usace.army.mil/Missions/ Engineering/StageandHydrologicData/HistoricalDischarges.aspx (accessed on 18 May 2016).

24. USGS Water Data for the Nation-Search for Sites with Data. Available online: http://waterdata.usgs.gov/ nwis (accessed on 18 May 2016).

25. Rego, J.L.; Meselhe, E.; Stronach, J.; Habib, E. Numerical modeling of the Mississippi-Atchafalaya rivers' sediment transport and fate: considerations for diversion scenarios. J. Coast. Res. 2010, 26, 212-229. [CrossRef]

26. Carnes, M.R.; Fox, D.N.; Rhodes, R.C.; Smedstad, O.M. Data assimilation in a North Pacific Ocean monitoring and prediction system. In Modern Approaches to Data Assimilation in Ocean Modeling; Malanotte-Rizzoli, P., Ed.; Elsevier: Amsterdam, The Netherlands, 1996; Volume 61, pp. 319-345.

27. Fox, D.N.; Teague, W.J.; Barron, C.N.; Carnes, M.R.; Lee, C.M. The Modular Ocean Data Assimilation System (MODAS). J. Atmos. Ocean. Technol. 2002, 19, 240-252. [CrossRef]

28. Rosmond, T.E. The design and testing of the navy operational global atmospheric prediction system. Weather Forecast. 1992, 7, 262-272. [CrossRef]

29. Hodur, R.M. The Naval Research Laboratory's Coupled Ocean/Atmosphere Mesoscale Prediction System (COAMPS). Mon. Weather Rev. 1997, 135, 1414-1430. [CrossRef]

30. Wanninkhof, R. Relationship between wind speed and gas exchange. J. Geophys. Res. Oceans 1992, 97, 7373-7382. [CrossRef]

31. Murrell, M.C.; Stanley, R.S.; Lehrter, J.C. Plankton community respiration, net ecosystem metabolism, and oxygen dynamics on the Louisiana continental shelf: Implications for hypoxia. Cont. Shelf Res. 2013, 52, 27-38. [CrossRef]

32. Hetland, R.D.; DiMarco, S.F. How does the character of oxygen demand control the structure of hypoxia on the Texas-Louisiana continental shelf? J. Mar. Syst. 2008, 70, 49-62. [CrossRef]

33. Jolliff, J.K.; Smith, T.A.; Barron, C.N.; deRada, S.; Anderson, S.C.; Gould, R.W.; Arnone, R.A. The impact of coastal phytoplankton blooms on ocean-atmosphere thermal energy exchange: Evidence from a two-way coupled numerical modeling system. Geophys. Res. Lett. 2012, 39. [CrossRef]

34. Zhao, J.; Barnes, B.; Melo, N.; English, D.; Lapointe, B.; Muller-Karger, F.; Schaeffer, B.; Hu, C. Assessment of satellite-derived diffuse attenuation coefficients and euphotic depths in south Florida coastal waters. Remote Sens. Environ. 2013, 131, 38-50. [CrossRef]

35. Martinolich, P.; Scardino, T. Automated Processing System User's Guide Version 4.2; NRL: Washington, DC, USA, 2011.

36. Lee, Z.P.; Du, K.P.; Arnone, R. A model for the diffuse attenuation coefficient of downwelling irradiance. J. Geophys. Res. Oceans 2005, 110. [CrossRef]

37. Schaeffer, B.A.; Sinclair, G.A.; Lehrter, J.C.; Murrell, M.C.; Kurtz, J.C.; Gould, R.W., Jr. An analysis of diffuse light attenuation in the northern Gulf of Mexico hypoxic zone using the SeaWiFS satellite data record. Remote Sens. Environ. 2011, 115, 3748-3757. [CrossRef] 
38. TRMM Online Visualization and Analysis System (TOVAS). Available online: http:/ /disc2.nascom.nasa. gov/Giovanni/tovas/ (accessed on 16 May 2016).

39. TRMM Monthly Rainfall Product 3B43 V7. Available online: http://disc.gsfc.nasa.gov/datacollection/ TRMM_3B43_V7.shtml (accessed on 16 May 2016).

40. Lehrter, J.C.; Beddick, D.L.; Devereux, R.; Yates, D.F.; Murrell, M.C. Sediment-water fluxes of dissolved inorganic carbon, $\mathrm{O}_{2}$, nutrients, and $\mathrm{N}_{2}$, from the hypoxic region of the Louisiana continental shelf. Biogeochemistry 2012, 109, 233-252. [CrossRef]

41. Obenour, D.R.; Scavia, D.; Rabalais, N.N.; Turner, R.E.; Michalak, A.M. Retrospective analysis of midsummer hypoxic area and volume in the Northern Gulf of Mexico, 1985-2011. Environ. Sci. Technol. 2013, 47, 9808-9815. [CrossRef] [PubMed]

42. Fennel, K.; Laurent, A.; Hetland, R.; Justić, D.; Ko, D.S.; Lehrter, J.; Murrell, M.; Wang, L.; Yu, L.; Zhang, W. Effects of model physics on hypoxia simulations for the northern Gulf of Mexico: A model intercomparison. J. Geophys. Res. 2016, in press.

43. Lohrenz, S.E.; Redalje, D.G.; Cai, W.-J.; Acker, J.; Dagg, M. A retrospective analysis of nutrients and phytoplankton productivity in the Mississippi River plume. Cont. Shelf Res. 2008, 28, 1466-1475. [CrossRef]

44. Green, R.E.; Gould, R.W. A predictive model for satellite-derived phytoplankton absorption over the Louisiana shelf hypoxic zone: Effects of nutrients and physical forcing. J. Geophys. Res. Oceans 2008, 113, C06005. [CrossRef]

(C) 2016 by the authors; licensee MDPI, Basel, Switzerland. This article is an open access article distributed under the terms and conditions of the Creative Commons Attribution (CC-BY) license (http://creativecommons.org/licenses/by/4.0/). 